\title{
Eğrisel Yüzeyli Tabakalı Kompozit Plakların Kritik Burkulma Yüklerine Etki Eden Parametrelerin Belirlenmesi
}

\author{
Cenk Yanen ${ }^{1}$, Murat Can Tanış ${ }^{2}$, Murat Yavuz Solmaz ${ }^{3 *}$ \\ ${ }^{1}$ Firat University, Faculty of Engineering, Departmant of Mechanical Engineering, Elazığ, Turkey, (ORCID: 0000-0002-5092-8734), cyanen@ @irat.edu.tr \\ ${ }^{2}$ Firat University, Faculty of Engineering, Departmant of Mechanical Engineering, Elazı ̆, Turkey, (ORCID: 0000-0001-6339-851X), murattanis18@gmail.com \\ $3^{*}$ Frrat University, Faculty of Engineering, Departmant of Mechanical Engineering, Elazı̆ğ, Turkey, (ORCID: 0000-0001-6394-0313), mysolmaz@,firat.edu.tr
}

(1st International Conference on Applied Engineering and Natural Sciences ICAENS 2021, November 1-3, 2021)

(DOI: 10.31590/ejosat.1012879)

ATIF/REFERENCE: Yanen, C., Tanış, M.C. \& Solmaz, M.Y. (2021). Eğrisel Yüzeyli Tabakalı Kompozit Plakların Kritik Burkulma Yüklerine Etki Eden Parametrelerin Belirlenmesi. European Journal of Science and Technology, (28), 1077-1082.

\section{$\ddot{O} \mathbf{z}$}

Bu çalışmada eğrisel yüzeyli tabakalı kompozit plakların burkulma yükü altındaki davranışlarına etki eden parametreler incelenmiştir. Bu amaçla farklı tabaka dizilimlerine, açılarına ve geometrik özelliklere sahip tabakalı hibrit kompozitlerin kritik burkulma yüklerindeki değişim sayısal olarak araştırılmıştır. Kompozit malzeme tasarımında fiber malzemesi olarak karbon, cam ve aramid fiber tercih edilmiş ve 6 farklı dizilim uygulanmıştır. Kumaş türünün yanı sıra oryantasyon açılarının kritik burkulma yükü üzerindeki etkisini inceleyebilmek için $0^{\circ}, 45^{\circ},-45^{\circ}$ ve $90^{\circ}$ açılarına sahip tek yönlü kumaşlar 6 farklı şekilde kullanılmıştır. Eğrisel yüzeyli kompozit plaklarda geometrik özelliklerin burkulma özellikleri üzerindeki etkisini gözlemleyebilmek için numuneler 4 farklı eğrilik yarıçapı ve 2 farklı eğrilik açısında tasarlanmıştır. Modelleme ANSYS paket programı kullanılarak yapılmıştır. Yapılan analizler sonucunda kritik burkulma yükleri belirlenerek kıyaslanmıştır. Eğrisel yüzeyli kompozit plaklarda eğrilik yarıçapı ve eğrilik açısı arttıkça kritik burkulma yükünün arttığı tespit edilmiştir.

Anahtar Kelimeler: Tabakalı hibrit kompozit, Eğrisel, modelleme, Ansys, burkulma.

\section{Determination of Parameters Affecting Critical Buckling Loads of Curved Laminated Composite Plates}

\begin{abstract}
In this study, parameters affecting the behavior of curved laminated composite plates under buckling load were investigated. For this purpose, the change in critical buckling loads of layered hybrid composites with different layer arrangements, angles and geometrical properties was investigated numerically. In the composite material design, carbon, glass and aramid fiber were preferred as fiber material and 6 different arrays were applied. In order to examine the effect of orientation angles on critical buckling load as well as fabric type, unidirectional fabrics with $0^{\circ}, 45^{\circ},-45^{\circ}$ and $90^{\circ}$ angles were used in 6 different ways. In order to observe the effect of geometric properties on buckling properties of curved laminated composite plates, the samples were designed with 4 different radius of curvature and 2 different curvature angles. Modeling was done using ANSYS program. As a result of the analysis, critical buckling loads were determined and compared. It has been determined that the critical buckling load increases as the radius of curvature and angle of curvature increase in curved laminated composite plates.
\end{abstract}

Keywords: Laminated hybrid composite, Curved, modeling, Ansys, buckling. 


\section{Giriş}

Kompozit malzemeler geleneksel malzemelerde bulunmayan mekanik, termal ve elektriksel özellikleri bir arada sunmak için tasarlanmış yapılardır. Sahip oldukları eşsiz özelliklerinden dolayı kompozit malzemeler, otomotiv, uzay, havacılık ve deniz endüstrisi, savunma sanayi, inşaat sektörü ve spor ekipmanları gibi pek çok alanda artan şekilde kullanılmaktadır [1]-[8]. Kompozit malzemeler matris ve fiber olmak üzere iki ana bileşenden oluşmaktadır [9], [10]. Matris malzemesi olarak genellikle epoksi ve polyester reçine kullanılmaktadır [11]-[14]. Fiber malzemesi olarak ise en çok kullanılan malzemeler; karbon, cam ve aramid fiberlerdir [15]-[18].

Farklı oryantasyonlardaki kompozit malzemelerin mekanik özelliklerine deniz suyunun etkisi Yüncüoğlu vd. tarafından incelenmiştir. $\mathrm{Bu}$ çalışmada kompozit malzemelerin mekanik özelliklerinin, geleneksel malzemelerden farklı olarak, üretiminde kullanılan matris ve fiber malzemesinin cinsi, doğrultusu, katman sayısı ve dizilimleri gibi bir çok değişkene bağlı olduğunu bildirilmiştir. Bunun yanısıra kompozit malzemelerin kullanıldıkları ortamında mekanik özellikler üzerinde etkisinin olduğu tespit edilmiştir [19].

Fiber malzemeler tek tek kullanılabildiği gibi kullanım alanının özelliklerine göre hibrit olarak bir arada kullanılması ve mekanik özelliklerinin belirlenmesi araştırmacıların oldukça ilgisini çekmiştir. Cam/karbon hibrit kompozit tabakaların burkulma dayanımının delaminasyonun etkisini Julias vd. tarafından araştırılmıştır. Dört farklı delaminasyon durumuna sahip simetrik ve antisimetrik tabaka dizilimleri için kritik burkulma yükleri tespit edilmiştir. Sonuç olarak yazarlar delaminasyonun yerinin ve konumunun kritik burkulma yükü üzerinde önemli etkisinin olduğunu bildirilmiştir [20]. Bası yükü altında dairesel delikli örgülü cam elyaf-epoksi kompozit plakların yük-deplasman davranışı Hakim vd. tarafindan incelenmiştir. Elde edilen sonuçlar tabakalı hibrit plaklar için malzeme tipi ve boyutunun oldukça önemli olduğunu göstermiştir [21]. Arun tarafından yapılan çalışmada örgülü cam-epoksi tabakalı kompozit plağın burkulma analizi üzerine çalışmalar yapılmıştır. Yazar çalışmasında uzunluk/kalınlık ve plak oryantasyonunun burkulma yüküne etkisini deneysel olarak incelemiştir [22].

Kadameli kesitli kompozit kavisli kirişlerin serbest titreşim analizini gerçekleştiren Bariki vd., kompozit kavisli kirişlerin titreşimlerini yapısal sönüm etkisini de ele alarak analiz yapmıştır. Ayrıca analizde geometrik parametreler, sınır şartları ve fiber oryantasyonu gibi farklı parametrelerin de etkisini göz önüne alındığında kirişlerin davranışlarının çalışmada önerilen yöntem ile iyi bir oranda tahmin edilebileceği bildirilmiştir [23].

Yukarıda verilen literatür çalışmalarından görülebileceği gibi; düz plaklar ve kiriş yapılar üzerine birçok çalışma yapılmış olmasına rağmen eğrisel yüzeyli kompozit yapılar üzerine yapılan çalışmalar sınırlı sayıdadır. Ayrıca incelenen çalışmalarda eğrisel yüzeyli kompozitlerde eğrilik yarıçapının, eğrilik açısının ve kompozit tabaka dizilim ve oryantasyon açılarının değişiminin burkulma yükü üzerindeki etkilerinin sayısal olarak incelendiği bir çalışmaya rastlanılmamıştır. Bu çalışmada, fiber mazlemesi olarak karbon, cam ve aramid fiberler kullanılarak modellenmiş eğrisel yüzeyli tabakalı hibrit kompozitlerin burkulma davranışları; eğrilik yarıçapı, kompozitlerin dizilimi ve açıları arasındaki oryantasyon ve yüzey alanındaki değişiklik dikkate alınarak incelenmiştir.

\section{Materyal ve Metot}

$\mathrm{Bu}$ çalışmada eğrisel yüzeyli tabakalı hibrit kompozitlerin kritik burkulma yükleri altındaki davranışları sayısal olarak incelenmiştir. Eğrisel yüzeyli kompozit plaklarda geometrik özelliklerin etkisini inceleyebilmek için görseli Şekil 1'de verilen numune tasarlanmıştır. Tasarlanan eğrisel yüzeyli kompozitlerin kritik burkulma yüklerine etki eden parametrelerin araştırılması için ayrıntıları Tablo 1'de verilen 4 farklı numune grubu oluşturulmuş ve modelleme buna göre yapılmıştır. Geometrik özelliklerin kritik burkulma yükü üzerindeki etkisinin incelenebilmesi için 2 farklı eğrilik açısı $\left(\theta_{0}\right)$ ve 4 farklı eğrilik yarıçapı (R) kullanılarak tasarım yapılmıştır. Eğrisel yüzeyli kompozit plaklarda kumaş diziliminin incelenebilmesi için kompozit plak üretiminde araştırmacılar tarafından en çok tercih edilen karbon, cam ve aramid fiberler tercih edilmiştir. Kritik burkulma yüküne etkisinin olacağı düşünülen bir diğer faktör de oryantasyon açısının değişimidir. Bu nedenle çalışmada tek yönlü kumaşlar $0^{\circ}, 45^{\circ},-45^{\circ}$ ve $90^{\circ}$ olmak üzere 5 farklı açıda kullanılmıştır. Kumaş kalınlıkları her fiberin kalınlığı $0,05 \mathrm{~mm}$ olarak kullanılmıştır. Toplam numune kalınlığımız (h) $0,25 \mathrm{~mm}$ olarak belirlenmiştir.

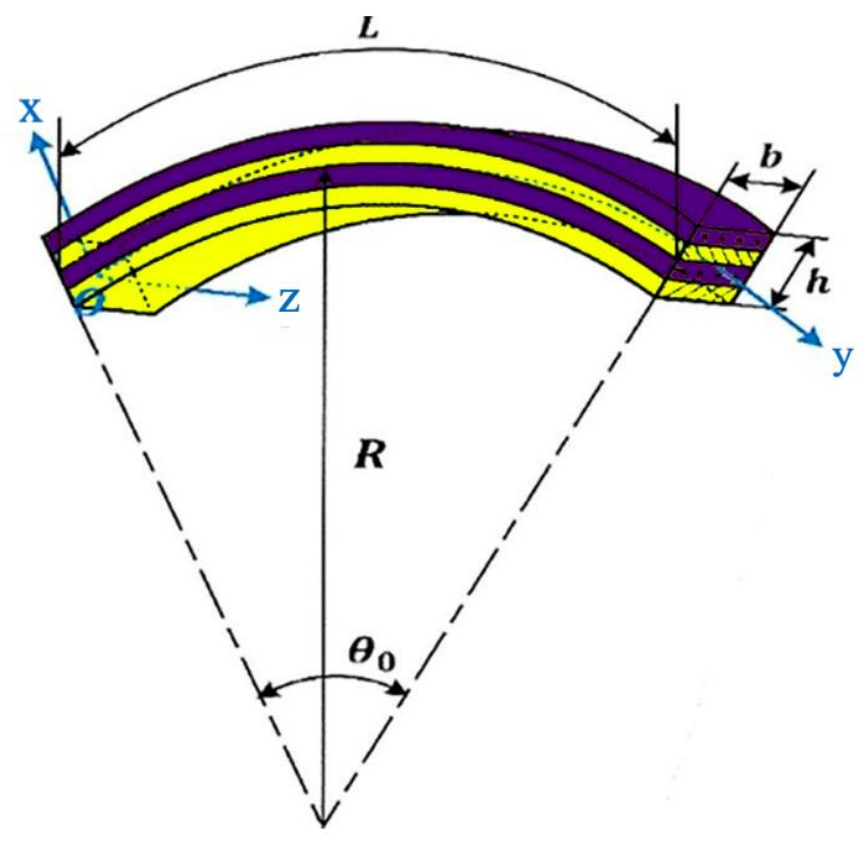

Şekil 1. Numune gösterimi

ANSYS 14.5 paket programında sonlu elemanlar yöntemiyle farklı eğrilik yarıçaplarda, farklı kumaş dizilimlerinde, farklı tabaka dizilimlerinde ve iki farklı eğrilik açısından oluşacak parametrelerin burkulma yüküne olan etkileri incelenmiştir.

Sayısal çalışmada modelleme kısmı için kullanılan malzeme özellikleri literatürden alınarak kullanılmıştır. Bahsedilen özellikler Tablo 2'de verilmiştir [24]. 
Tablo 1. Modellemede kullanılan numune tasarım planı

\begin{tabular}{|c|c|c|c|c|}
\hline Araştırılan Faktör & Eğrilik Açısı & Eğrilik Yarıçapı & Tabaka Dizilimi & Oryantasyon Açıları \\
\hline Tabaka Dizilimi & $90^{\circ}$ & $7 \mathrm{~mm}$ & $\begin{array}{l}\mathrm{K} / \mathrm{G} / \mathrm{A} / \mathrm{G} / \mathrm{K}] \\
{[\mathrm{G} / \mathrm{K} / \mathrm{A} / \mathrm{K} / \mathrm{G}]} \\
{[\mathrm{A} / \mathrm{K} / \mathrm{G} / \mathrm{K} / \mathrm{G}]} \\
{[\mathrm{A} / \mathrm{G} / \mathrm{K} / \mathrm{G} / \mathrm{K}]} \\
{[\mathrm{K} / \mathrm{G} / \mathrm{K} / \mathrm{G} / \mathrm{A}]} \\
{[\mathrm{G} / \mathrm{K} / \mathrm{G} / \mathrm{K} / \mathrm{A}]}\end{array}$ & {$[0 /-45 / 90 / 45 / 0]$} \\
\hline Oryantasyon Açıları & $90^{\circ}$ & $7 \mathrm{~mm}$ & {$[\mathrm{~K} / \mathrm{G} / \mathrm{K} / \mathrm{G} / \mathrm{A}]$} & $\begin{array}{l}{[0 /-45 / 90 / 45 / 0]} \\
{[0 / 45 / 90 /-45 / 0]} \\
{[0 / 90 / 45 /-45 / 0]} \\
{[0 /-45 / 45 / 90 / 0]} \\
{[90 / 0 / 45 / 0 /-45]} \\
{[-45 / 0 / 90 / 0 / 45]}\end{array}$ \\
\hline Ĕ̈rilik Yarıçapı & $90^{\circ}$ & $\begin{array}{l}3 \mathrm{~mm} \\
5 \mathrm{~mm} \\
7 \mathrm{~mm} \\
9 \mathrm{~mm}\end{array}$ & {$[\mathrm{G} / \mathrm{K} / \mathrm{A} / \mathrm{K} / \mathrm{G}]$} & {$[0 /-45 / 90 / 45 / 0]$} \\
\hline Ĕgrilik Açısı & $90^{\circ}$ & $\begin{array}{l}3 \mathrm{~mm} \\
5 \mathrm{~mm} \\
7 \mathrm{~mm} \\
9 \mathrm{~mm} \\
3 \mathrm{~mm} \\
5 \mathrm{~mm} \\
7 \mathrm{~mm} \\
9 \mathrm{~mm}\end{array}$ & {$[\mathrm{G} / \mathrm{K} / \mathrm{A} / \mathrm{K} / \mathrm{G}]$} & {$[0 /-45 / 90 / 45 / 0]$} \\
\hline
\end{tabular}

Tablo 2. Kumaşların mekanik özellikleri

\begin{tabular}{|c|c|c|c|c|c|c|c|c|c|}
\hline Kumaş Adı & $E_{x}(M P a)$ & $\mathrm{E}_{\mathbf{y}}(\mathrm{MPa})$ & $\mathrm{E}_{\mathrm{z}}(\mathrm{MPa})$ & $v_{\mathrm{xy}}$ & $v_{y z}$ & $v_{\mathrm{xz}}$ & $\mathrm{G}_{\mathrm{xy}}(\mathrm{MPa})$ & $\mathrm{G}_{\mathrm{yz}}(\mathrm{MPa})$ & $\overline{G_{x z}(\mathrm{MPa})}$ \\
\hline Karbon (K) & $1,81 \times 10^{5}$ & $1,03 \times 10^{4}$ & $1,03 \times 10^{4}$ & 0,28 & 0,28 & 0,28 & 7170 & 7170 & 7170 \\
\hline $\operatorname{Cam}(G)$ & $1,19 \times 10^{5}$ & $9,28 \times 10^{3}$ & $9,28 \times 10^{3}$ & 0,34 & 0,59 & 0,34 & 4640 & 2930 & 4640 \\
\hline $\operatorname{Aramid}(A)$ & $2,1 \times 10^{4}$ & $2,1 \times 10^{4}$ & $1 \times 10^{4}$ & 0,3 & 0,26 & 0,26 & 3700 & 2000 & 2000 \\
\hline
\end{tabular}

Çalışmamızda; toplamda 5 tabaka için; 2 tabaka cam fiber, 2 tabaka karbon fiber ve 1 tabaka aramid fiber kullanılmışırı. Tabakaların dizilimi, oryantasyon açıları ve kalınlıkları Şekil 2'de görülmektedir.

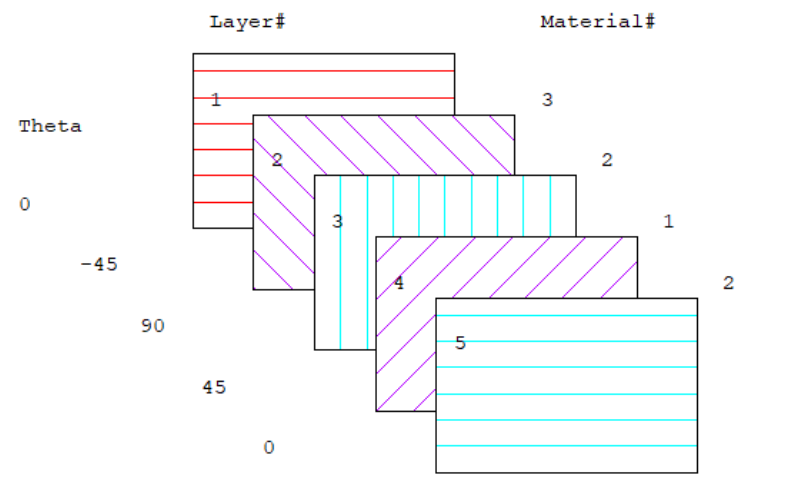

Şekil 2. Oryantasyon açılarının görüntülernmesi
Şekil geometrisi için eğrilik yarıçapı, uzunluk ve eğrisel yüzey elde etmek için kullanılacak olan silindirin açı değerleri tanımlanarak model oluşturulmuştur. Model oluşturulduktan sonra numune sonlu elemanlarına ayrılmıştır. Model ortalama 490 dügüm ve 442 elemandan oluşmuştur. Mesh aralıkları sürekli eşit olup aynı hassasiyette ilerlemek için aralıklar sabit tutulmuştur. $\mathrm{Bu}$ çalışmada statik analiz yapılmıştır. Araştırma için belirlenen sınır şartları alt eğrisel alanın tamamının her yönden sabitlenmiştir. Üst eğrisel alanından $1 \mathrm{MPa}$ kuvvet uygulanmış ve kuvvet uygulanan yerden $\mathrm{x}$ ve y yönündeki dönmeye kısıtlanmıştır (Şekil 3a). Kompozitin tabaka yapıs1 ve üç boyutlu görünümü Şekil 3b.'de gösterilmektedir. Gerçekleştirilen analizlerden elde edilen sonuçlar Şekil 4'de verilmiştir. 


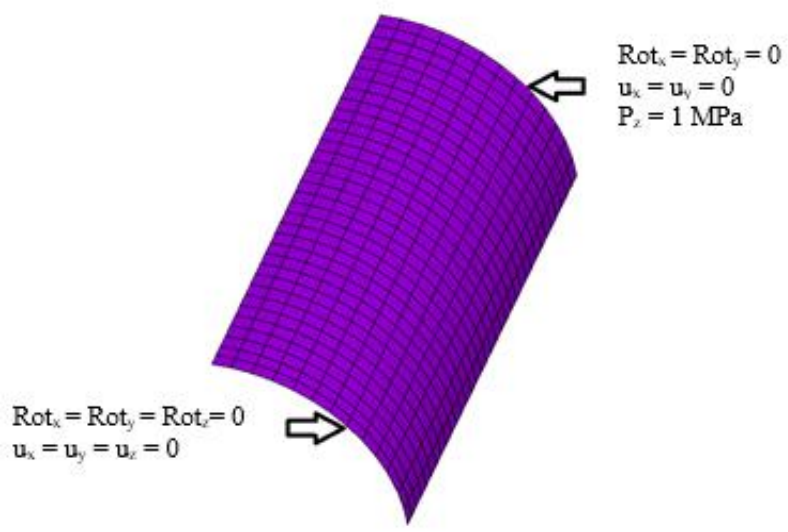

a)

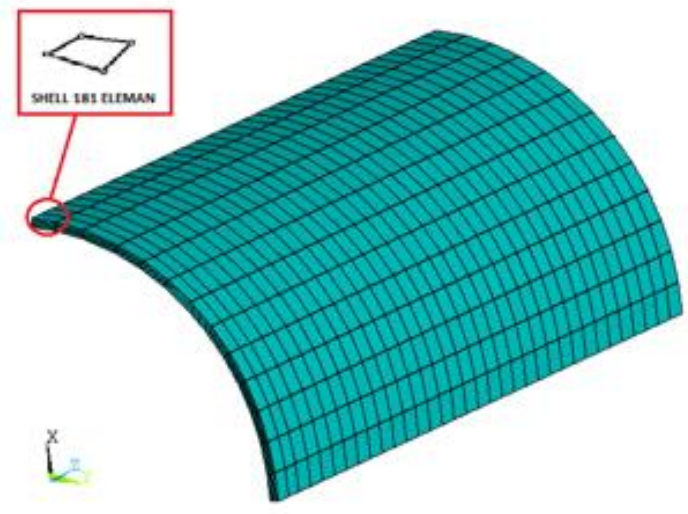

b)

Şekil 3. a)Sınır şartları b) sonlu eleman ă̆ yapısı
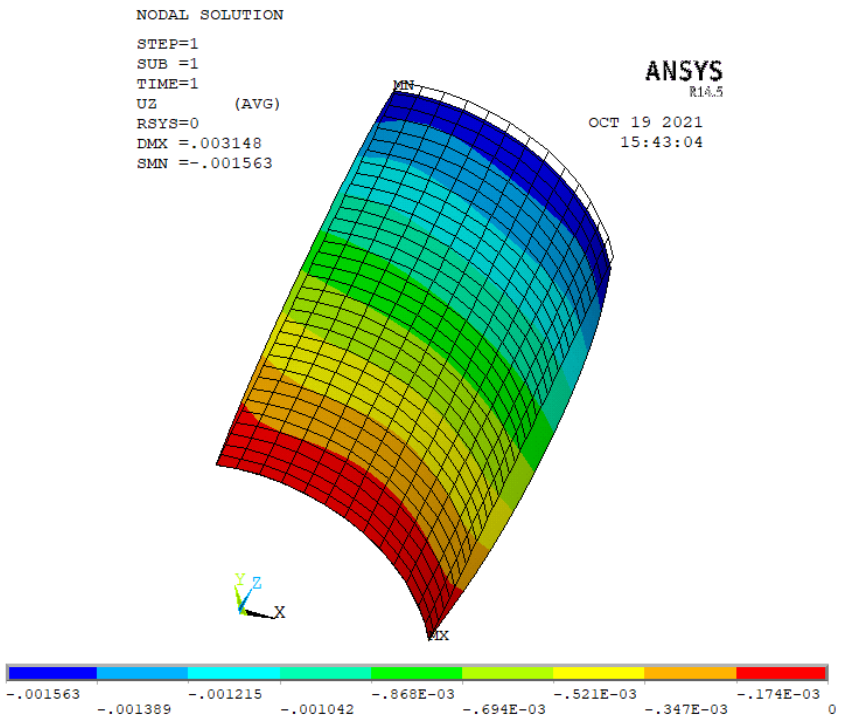

Şekil 4. Analiz sonuçlarının görüntülenmesi

\section{Bulgular ve Tartışma}

Eğrisel yüzeyli hibrit kompozit plaklarda kritik burkulma yüküne etki eden parametreler incelenmiştir. Oryantasyon açılarının değişiminin $P k r$ yükü üzerindeki etkisi $[\mathrm{K} / \mathrm{G} / \mathrm{K} / \mathrm{G} / \mathrm{A}]$ dizilimine sahip $7 \mathrm{~mm}$ çapında ve $20 \mathrm{~mm}$ uzunluğunda $90^{\circ}$ eğrilik açısındaki numuneler kullanılarak araştırılmış ve sonuçları Şekil 5 'de verilmiştir.

Şekil 5'de oryantasyon açısının değişiminin kritik burkulma yükü üzerindeki etkisi görülmektedir. En düşük $\mathrm{Pkr}$ yükü [0/90/45/-45/0] numunede, en yüksek $\mathrm{Pkr}$ değeri ise [0/45/90/45/0] numunede meydana gelmiştir. En yüksek Pkr değerinin en düşük Pkr değerine göre \%18,46 daha yüksek olduğu belirlenmiştir. $\mathrm{Bu}$ durum oryantasyon açısı değişiminin kritik burkulma yükü üzerindeki etkisini ortaya koymuştur. [0/45/90/$45 / 0]$ ve [0/-45/90/45/0] dizilimine sahip numuneler incelendiğinde, numune dizilimleri birbirlerine çok benzer olduğu için Pkr değerlerinin birbirine çok yakın olduğu bulunmuştur. [0/90/45/-45/0] ile [0/45/-45/90/0] yakın çünkü kumaş dizilimleri birbirine yakın şekilde dizilmiştir. [90/0/-45/0/45]ile [45/0/90/0/45] yakın çünkü en diştaki dizilimlerde düşey yönde tutacak lifler bulunmaktadır.

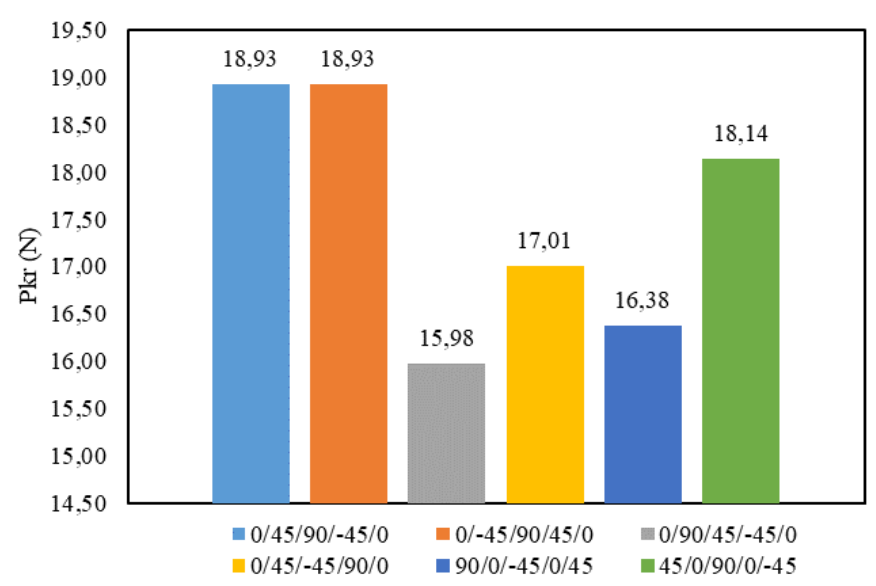

Şekil 5. Oryantasyon açılarının değişiminin incelenmesi

Kumaş dizilimlerinin değişiminin $\mathrm{Pkr}$ yükü üzerindeki etkisi [0/-45/90/45/0] dizilimine sahip $7 \mathrm{~mm}$ çapında ve $20 \mathrm{~mm}$ uzunluğunda $90^{\circ}$ eğrilik açısındaki numuneler kullanılarak araştırılmış ve sonuçları Şekil 6'da verilmiştir.

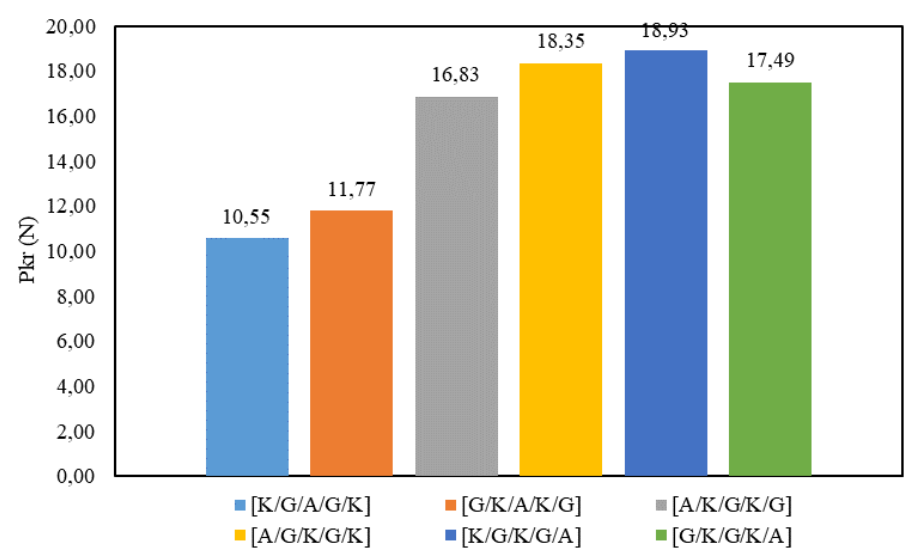

Şekil 6. Kumaş diziliminin etkisinin incelenmesi

Şekil 6'da tabaka dizilimindeki değişimlerin kritik burkulma yükü üzerindeki etkisi görülmektedir. En düşük kritik burkulma yükü $[\mathrm{K} / \mathrm{G} / \mathrm{A} / \mathrm{G} / \mathrm{K}]$ numunede, en yüksek değeri ise $[\mathrm{K} / \mathrm{G} / \mathrm{K} / \mathrm{G} / \mathrm{A}]$ numunede meydana gelmiştir. En yüksek $\mathrm{Pkr}$ değerinin en düşük 
Pkr değerine göre \% 79,72 daha yüksek olduğu görülmektedir. Bu durum tabaka dizilimindeki değişimin kritik burkulma yükü üzerindeki etkisini ortaya koymuştur. Bu grafikten yola çıkarak aramid'in merkezde olması durumunda kritik burkulma yükleri düşükken aramid fiberin kenarlarda kullanılması durumunda kritik burkulma yükünün arttığını görülmüştür.

Eğrilik yarıçaplarındaki değişiminin $\mathrm{Pkr}$ yükü üzerindeki etkisi [0/-45/90/45/0] oryantasyon dizilimine, [G/K/A/K/G] tabaka dizilimine ve $20 \mathrm{~mm}$ uzunluğunda $90^{\circ}$ eğrilik açısındaki numuneler kullanılarak araştırılmış ve sonuçları Şekil 7 'de verilmiştir.

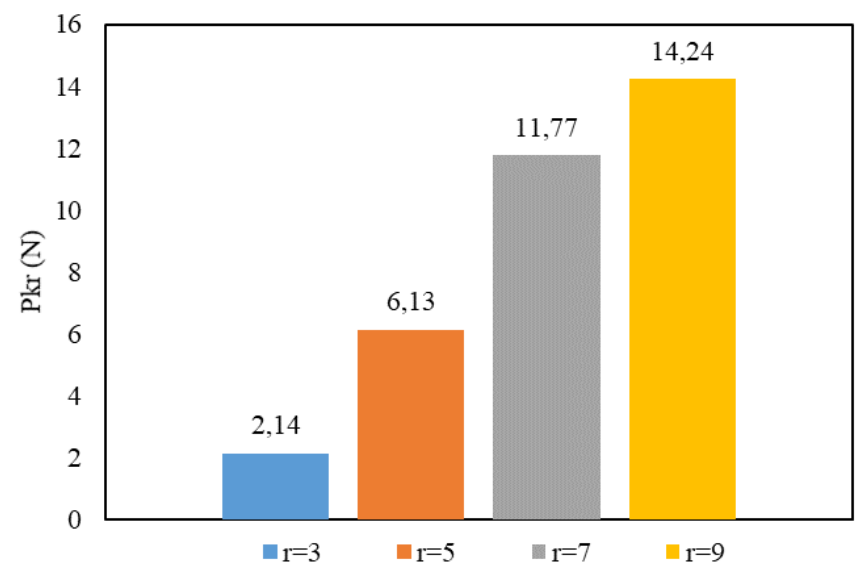

\section{Şekil 7. Eğrilik yarıçapının değişiminin incelenmesi}

Şekil 7'de eğrilik yarıçapındaki değişiminin kritik burkulma yükü üzerindeki etkisi görülmektedir. En düşük $\mathrm{Pkr} \mathrm{r}=3 \mathrm{~mm}$ numunede en yüksek değeri $\mathrm{r}=9 \mathrm{~mm}$ olan numunede meydana gelmiştir. En düşük Pkr değerinin en yüksek Pkr değerine göre \% 84,97 daha düşük olduğu görülmektedir. Bu grafikten yola çıkarak eğrilik yarıçapı arttıkça kritik burkulma yükünün arttırdığı görülmüştür. Eğrilik yarıçapı yüksek olan parçaların daha yüksek burkulma yüklerine dayanabildiği tespit edilmiştir.

Eğrilik açılarındaki değişiminin $\mathrm{Pkr}$ yükü üzerindeki etkisi [0/-45/90/45/0] oryantasyon dizilimine, $[\mathrm{G} / \mathrm{K} / \mathrm{A} / \mathrm{K} / \mathrm{G}]$ tabaka dizilimine ve $20 \mathrm{~mm}$ uzunluğunda belirlenen tüm eğrilik yarıçaplarının bulunduğu numuneler kullanılarak araştırılmış ve sonuçları Şekil 8'de verilmiştir.

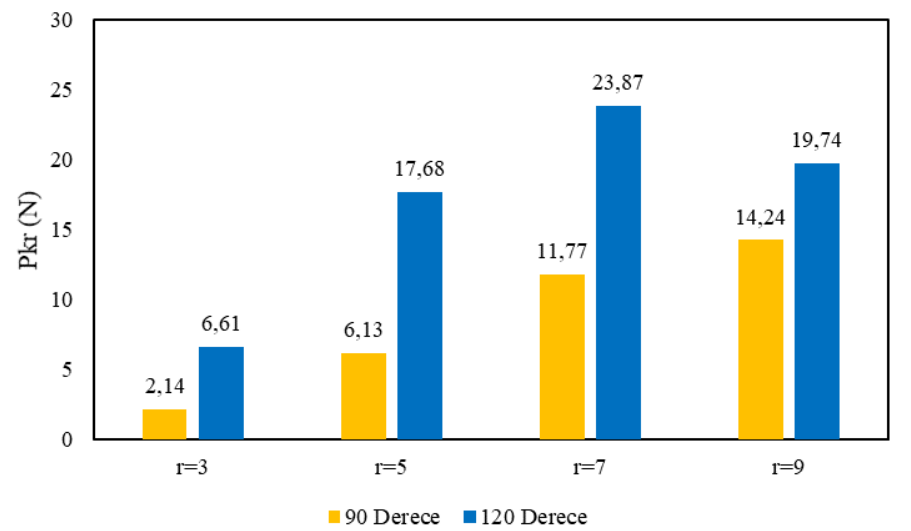

\section{Şekil 8. Derecenin değişiminin etkisinin incelenmesi}

Şekil 8'de eğrilik açısının değişiminin kritik burkulma yükü üzerindeki etkisi görülmektedir. En düşük $\mathrm{Pkr}$ yükü $90^{\circ}, \mathrm{r}=3 \mathrm{~mm}$ numunede en yüksek $\mathrm{Pkr}$ değeri ise $120^{\circ}, \mathrm{r}=7 \mathrm{~mm}$ numunede meydana gelmiştir. En düşük $\mathrm{Pkr}$ değerinin en yüksek $\mathrm{Pkr}$ değerine göre \% 91,03 daha düşük olduğu görülmektedir. Bu durum eğrilik açısı değişiminin kritik burkulma yükü üzerindeki etkisini ortaya koymuştur. $90^{\circ}, \mathrm{r}=3 \mathrm{~mm}$ ve $120^{\circ}, \mathrm{r}=3 \mathrm{~mm}$ eğrilik açılarına sahip numuneler incelendiğinde bir artış görülmektedir. Aynı eğrilik yarıçapına sahip diğer tüm numunelerde incelendiğinde eğrilik açısı arttıkça kritik burkulma yükünde artış görülmektedir.

\section{Sonuçlar}

$\mathrm{Bu}$ çalışmada eğrisel yüzeyli tabakalı hibrit kompozit plakların burkulma yükü altındaki davranışlarına etki eden parametreler sayısal olarak incelenmiştir. Tabakalı hibrit kompozit plakların oryantasyon açıları, tabaka dizilimleri, eğrilik yarıçapları ve eğrilik açıları değiştirilmiş ve kritik burkulma yükleri belirlenmiştir. ANSYS paket programı kullanılarak yapılan analizlerin sonuçları incelendiğinde elde edilen sonuçlar aşağıda maddeler halinde verilmiştir:

- İncelenen grafik ve verilerin ışığında en yüksek kritik burkulma yükü $[\mathrm{G} / \mathrm{K} / \mathrm{A} / \mathrm{K} / \mathrm{G}]$ tabaka dizilimli, [0/45/90/45/0] oryantasyona sahip, $7 \mathrm{~mm}$ eğrilik yarıçap1 ve $120^{\circ}$ eğrilik açısına sahip numunede $23,87 \mathrm{~N}$ olarak gözlemlenmiştir.

- En düşük kritik burkulma yükü $[\mathrm{G} / \mathrm{K} / \mathrm{A} / \mathrm{K} / \mathrm{G}]$ tabaka dizilimli, [0/-45/90/45/0] oryantasyona sahip, $3 \mathrm{~mm}$ eğrilik yarıçapı ve $90^{\circ}$ eğrilik açısına sahip olan numunede 2,14 $\mathrm{N}$ olarak tespit edilmiştir.

- Oryantasyon açılarının değişiminden kaynaklı farklılıkların sebebini düşey yüklere dayanabilen $45^{\circ}$, $90^{\circ},-45^{\circ}$ yönlerindeki lifler merkez düzlemde kullanıldığı zaman kritik burkulma yüklerinde düşüş gözlemlendiği, bu liflerin merkez düzlemden diş yüzeylere yerleştirildiği durumda ise kritik burkulma yüklerinde artış olduğu gözlemlenmiştir.

- Tabaka dizilimleri göz önüne alındığında aramid fiber kumaşların kritik burkulma yükünü arttırdığ1 tespit edilmiştir. Bu kumaş merkez düzlemde kullanıldığında burkulma yük değerleri düşük çıkarken kumaş merkez düzlemin dışına kaydırıldığında burkulma yük değerlerinin arttığı belirlenmiştir.

- Eğrilik yarıçapları değişiminin etkisi incelendiğinde, eğrilik yarıçapı arttıkça kritik burkulma yükü dayanımını da arttığı görülmüştür.

- Eğrilik açıları değişiminden eğrilik açısı arttıkça kritik burkulma yükünün arttığı tespit edilmiştir.

$\mathrm{Bu}$ çalışmadan elde edilen bilgiler 1şı̆̆ında: Aramid kumaşının merkez düzlemden daha ziyade merkezden daha uzakta olan diş düzlemlerde kullanılmasının ilave olarak üretim parametrelerinin müsaade ettiği oranda büyük eğrilik yarıçapı ve eğrilik açıları tercih edilmesinin burkulma direnci anlamında pozitif katkı yapacağı sonucuna varılmıştır. 


\section{Kaynaklar}

S. Sajan and D. Philip Selvaraj, "A review on polymer matrix composite materials and their applications," Mater. Today Proc., vol. 47, pp. 5493-5498, 2021, doi: https://doi.org/10.1016/j.matpr.2021.08.034.

J. Jeremy Jeba Samuel, R. Ramadoss, K. N. Gunasekaran, K. Logesh, S. J. P. Gnanaraj, and A. A. Munaf, "Studies on mechanical properties and characterization of carbon fiber reinforced hybrid composite for aero space application," Mater. Today Proc., 2021, doi: https://doi.org/10.1016/j.matpr.2021.05.304.

M. Naito et al., "Applicability of composite materials for space radiation shielding of spacecraft," Life Sci. Sp. Res., vol. 31, pp. 71-79, 2021, doi: https://doi.org/10.1016/j.lssr.2021.08.004.

M. S. Sarfraz, H. Hong, and S. S. Kim, "Recent developments in the manufacturing technologies of composite components and their cost-effectiveness in the automotive industry: A review study," Compos. Struct., vol. 266, p. 113864, 2021, doi: https://doi.org/10.1016/j.compstruct.2021.113864.

N. Gort, O. Döbrich, S. Grieder, M. Küng, and C. Brauner, "Experimental analysis of orthotropic strength properties of non-crimp fabric based composites for automotive leaf spring applications," Compos. Struct., vol. 271, p. 114154, 2021, doi: https://doi.org/10.1016/j.compstruct.2021.114154.

Y. M. Zhu, "Performance of Ti2AlC composite material in sports equipment," Sci. Technol. Mater., vol. 30, no. 2, pp. 99-102, 2018, doi: https://doi.org/10.1016/j.stmat.2018.02.004.

C. Yanen and M. Y. Solmaz, "Ballistic tests of lightweight hybrid composites for body armor," Mater. Test., vol. 61, no. 5, pp. 425-433, 2019, doi: doi:10.3139/120.111336.

M. Helal and E. Fathallah, "Finite element analysis and design optimization of a non-circular sandwich composite deep submarine pressure hull," Mater. Test., vol. 62, no. 10, pp. 1025-1032, 2020, doi: doi:10.3139/120.111580.

M. P. Westman, L. S. Fifield, K. L. Simmons, S. Laddha, and T. A. Kafentzis, "Natural fiber composites: a review," 2010.

S. D. S. Kopparthy and A. N. Netravali, "Review: Green composites for structural applications," Compos. Part C Open Access, vol. 6, p. 100169, 2021, doi: https://doi.org/10.1016/j.jcomc.2021.100169.

Z. Zhang, K. Fu, and Y. Li, "Improved interlaminar fracture toughness of carbon fiber/epoxy composites with a multiscale cellulose fiber interlayer," Compos. Commun., vol. 27, p. 100898 , 2021 ,

doi: https://doi.org/10.1016/j.coco.2021.100898.

M. Y. Mahmoud Zaghloul, M. M. Yousry Zaghloul, and M. M. Yousry Zaghloul, "Developments in polyester composite materials - An in-depth review on natural fibres and nano fillers," Compos. Struct., vol. 278, p. 114698, 2021, doi: https://doi.org/10.1016/j.compstruct.2021.114698.

R. Orhan, E. Aydoğmuş, S. Topuz, and H. Arslanoğlu, "Investigation of thermo-mechanical characteristics of borax reinforced polyester composites," J. Build. Eng., vol. 42, p. 103051 , 2021 ,

doi: https://doi.org/10.1016/j.jobe.2021.103051.

Y. E. Erdoğdu, E. E. Korkmaz, and Ş. Temiz, "Effect of graphene nanoplatelet filling on mechanical properties of natural fiber reinforced polymer composites," Mater. Test., vol. 63, no. 4, pp. 322-328, 2021, doi: doi:10.1515/mt-2020-0046.

D. May, C. Goergen, and K. Friedrich, "Multifunctionality of polymer composites based on recycled carbon fibers: A review," Adv. Ind. Eng. Polym. Res., vol. 4, no. 2, pp. 70-81, 2021, doi: https://doi.org/10.1016/j.aiepr.2021.01.001.

J. Du et al., "A review on machining of carbon fiber reinforced ceramic matrix composites," Ceram. Int., vol. 45, no. 15, pp. 18155-18166, 2019 , doi: https://doi.org/10.1016/j.ceramint.2019.06.112.

P. S. Hatti, S. K. L., A. B. Somanakatti, and R. M., "Investigation on tensile behavior of glass-fiber reinforced polymer matrix composite with varying orientations of fibers," Mater. Today Proc., 2021, doi: https://doi.org/10.1016/j.matpr.2021.08.196.

B. Zhang, L. Jia, M. Tian, N. Ning, L. Zhang, and W. Wang, "Surface and interface modification of aramid fiber and its reinforcement for polymer composites: A review," Eur. Polym. J., vol. 147, p. 110352, 2021, doi: https://doi.org/10.1016/j.eurpolymj.2021.110352.

E. Uğur Yüncüoğlu, S. Turgut Ince, and E. Bağc1, "Strength of carbon fiber/epoxy in sea water," Mater. Test., vol. 63, no. 9, pp. 811-815, 2021, doi: doi:10.1515/mt-2021-0005.

A. Julias, S. Mohmeed, and V. Murali, "Effect of delamination on buckling strength of unidirectional glass-carbon hybrid laminates," Indian J. Eng. Mater. Sci., vol. 21, pp. 23-29, Mar. 2014.

H. Aljibori et al., "Load-displacement behavior of glass fiber/epoxy composite plates with circular cut-outs subjected to compressive load," Mater. Des. - MATER Des., vol. 31, pp. 466-474, Jan. 2010, doi: 10.1016/j.matdes.2009.07.005.

A. K. R, "Buckling Analysis of Woven Glass epoxy Laminated Composite Plate," National Institute of Technology Rourkela, 2009.

S. Khodabakhshpour-Bariki, R.-A. Jafari-Talookolaei, M. Attar, and A. Eyvazian, "Free vibration analysis of composite curved beams with stepped cross-section," Structures, vol. 33, pp. 4828-4842, 2021, doi: https://doi.org/10.1016/j.istruc.2021.07.041.

B. Beylergil, M. Tanoğlu, and E. Aktaş, "Mode-I fracture toughness of carbon fiber/epoxy composites interleaved by aramid nonwoven veils," Steel Compos. Struct., vol. 31, pp. 113-123, Apr. 2019, doi: 10.12989/scs.2019.31.2.113. 